\title{
Global Business: Virtual Workplaces and Collaborations
}

\author{
Dr. Kamlesh Mehta \\ Chair, Department of Management and Marketing \\ Professor of International Business and Marketing \\ National University \\ USA \\ Dr. Vivek Shah \\ Professor of CIS and Honorary Professor of International Studies \\ Texas State University \\ USA
}

\begin{abstract}
The state of the art in technologies and their impact on individuals, organizations, society and governments are on the rise. With constant and rapid innovation in the IT domain, many global organizations are moving to virtual team structures in order to build high performance cultures, improve productivity, and maintain synchronicity within their global structure. Many companies have had success in forming global virtual teams, though many have failed. The purposes of this paper are: (1) explore the use of virtual collaborations in global organizations, (2) explain virtual teams vs. physical teams, (3) address the pros and cons of virtual teams, (4) review the impact of the factors that affect the effectiveness of virtual teams, and (5) understand the new kind of worker and the role of the management.
\end{abstract}

Keywords/JEL: Virtual Collaboration, Virtual Teams, Virtual Meeting, Virtual Workplace, Virtual Business, Global Workplace, Global Teams, Global Business.

\section{Introduction}

The state of the art in technologies and their impact on individuals, organizations, society and governments are on the rise. The changing landscape of work environment, work stress and employee performance have every organization on its heels and toes. The working environment and work stress significantly influences employee performance (Rahayu, 2019).With constant and rapid innovation in the IT domain, many global organizations are moving to virtual team structures in order to build high performance cultures, improve productivity, and maintain synchronicity within their global structure. Many companies have had success in forming global virtual teams, though many have failed.

As technology improves, there is a question of increasing effectiveness of virtual teams. It is currently accepted that virtual teams are typically less productive than traditional face to face teams. Global organizations span many time zones, and so temporal variances can play a large factor for teams whose members reside in time zones with substantial time differences. Bandwidth of communication can also be a hindrance for global organizations as well. Teams that need to share data remotely face problems when dealing with large or intricate sets of data. Virtual teams that suffer from low communication bandwidth take longer to transfer information among the disparate members within the team.

Finally, virtual teams face a less quantitative problem when dealing with the quality of information transmitted between team members. Traditional team communication often consists of affectations and behaviors that can change the meaning of information. A shrug, a pause, or even a smile can change the meaning of information given verbally. For example, it is very difficult to impart sarcasm when using a text based communication medium. However, in person, sarcasm can be easily conveyed. Virtual teams often have difficulty with forming strong bonds between members for this reason. When implementing virtual teams, a global organization must remember that it is necessary to consider these problems when choosing both the coordination technology, and the team members themselves.

The purposes of this paper are: (1) explore the use of virtual collaborations in global organizations, (2) explain virtual teams vs. physical teams, (3) address the pros and cons of virtual teams, (4) review the impact of the factors that affect the effectiveness of virtual teams, and (5) understand the new kind of worker and the role of the management.

Virtual workplace is usually in a network of various workplace which connects people via private network or internet without concern for geographical boundaries or need for a centralized physical space. Therefore, it is located at several different physical places in the form of network of numerous workplaces. 
Virtual teams are multi-member teams that span more than one physical location and utilize indirect methods of communication in order to achieve an objective. Virtual teams are also known as dispersed teams, whereas the physical teams are known as collected teams. The future belongs to Dispersed (virtual) teams; collected teams (physical) will be thing of the past.

"Virtual" teams - ones made up of people in different physical locations-are on the rise. As companies expand geographically and as telecommuting becomes more common, work groups often span far-flung offices, shared workspaces, private homes, and hotel rooms.

The utilization of virtual teams increased dramatically in the 1990s and continues to grow today. With the growth of the internet and the rapidly decreasing cost of IT systems, global organizations are now more empowered to implement IT systems that enable cross country communication. The current trend of increasing globalization also necessitates the use of virtual teams. As organizations expand into multiple countries and time zones the efficiency of virtual teams can attribute to competitive advantage, or conversely, can inhibit growth.

\section{Dispersed (Virtual) vs. Collected Teams (Physical)}

Throughout the 1970s and 1980s, limited technology made remote communication challenging. Sharing information often relied on hand written letters, although some companies began to take advantage of digital communications, such as email and bulletin boards. Some early IT systems, such as Lotus Notes and proprietary communications systems, allowed some organizations to share more complex data, such as spreadsheets and database information. These systems were difficult to use and had limited bandwidth. Verbal communication took place over phone systems, often limited to point to point calls. Teams with members in more than two locations could not easily communicate in real time. These early systems lacked the ability to share video in real time. They also did not offer means to share graphical images, designs, or sketches in real time. In addition, these methods of communications contributed to

As technology has improved, virtual teams have been able to share more information in real time. Today, teams can communicate with hundreds of remote locations. Globalization is making "virtual communication" a necessity. Initially, cost of travel and later threat of terrorism has made virtual conference essential.

Video conferencing has become common in large organizations and whiteboard sharing allows virtual teams to share ideas and images immediately. Still, despite the improvements in technology, virtual teams often suffer from internal dissonance. Time differences between individuals continue to have a large negative impact on virtual team performance. Also, despite having access to video and high quality audio, team members have difficulties expressing nuanced information that can be more easily made in face to face communications. Often video communications are not of sufficient fidelity to impart facial expressions, gestures, or body language. Audio communications can remain cumbersome, particularly with a large number of participants. Audio quality can also suffer. For example, large rooms with speakerphones can fail to capture whispers or sighs. Participants still feel isolated from the conversation and may be disinclined to actively participate in a discussion.

Trust is a key factor in the effectiveness of virtual teams. Virtual teams that do not have a great deal of trust often fail to work well together and usually do not make a substantial effort to overcome the challenges inherent in working remotely. Remote communication takes more effort than face to face communication. For example, in order to host a discussion with a remote teammate, team members often have to schedule a conference time, reserve a conference room, and activate all the necessary IT systems to enable communication. Face to face communication is far simpler, even with advanced technologies.

Because of these problems, virtual teams typically communicate less frequently than face to face teams. Since communications are less frequent, having a high degree of trust in team members is important. Individual members in a virtual team must be more independent, and all members need to feel comfortable with the abilities and productivity of each member. Without a significant level of trust, virtual teams often find themselves unable to effectively distribute workloads and may have poor efficiency because of duplicate effort or poor coordination. Furthermore, virtual teams have a greater challenge in creating trust between team members since members are often left feeling isolated from the rest of the team.

\section{Issues}

In early 2000, May and Carter's (2001) article, “A case study of virtual team working in the European automotive industry," the Team-based European Automotive Manufacture project (TEAM) provides an excellent case study on the use of technology to improve communications among virtual teams. In this project, TEAM developed an IT system that enabled team members to communicate and share data on automotive component designs. 
The process used to develop the system was carefully planned, and the results carefully evaluated. The study primarily focused on the utility offered by the designed system, so no significant data relating to team member dynamics was captured. May and Carter (2001) discovered is that the TEAM project was able to leverage the new system to great effect. By allowing team members to quickly and easily share designs and technical data, the system increased efficiency for the team. Since designs could be transmitted faster, and discussed and improved upon in real time, quality for the final designs improved overall. The level of interaction needed by the remote members of TEAM was high. According to the authors, "development engineers from the automotive manufacturers involved in the TEAM project estimated that, on average, about $70 \%$ of their time may be spent on activities concerting remotely located suppliers" (May \& Carter, 2001). By reducing the amount of time spent coordinating with remote suppliers, TEAM was able to focus on increasing both the quality and quantity of their designs. Designs could also be produced more rapidly.

In another situation, the employee shared efforts fostered by tools and technology in the form of social media resulted in an increase in productivity by around $25 \%$ at chipmaker Xilinx (Ferrazzi, 2012).However, not all virtual collaborations are successful. A 2005 Deloitte study of IT projects outsourced to virtual work groups found that $66 \%$ failed to satisfy the clients' requirements (Ferrazzi, 2014). In their research, Ferrazzi (2014) discovered that most people consider virtual communication less productive than face-to-face interaction, and nearly half admit to feeling confused and overwhelmed by collaboration technology.

Moreover, there are many issues in virtual teams that can lead to the project failure. Among these issues addressed in this paper include trust, organization of the team, technology, management, and a new kind of worker.

\subsection{The Importance of Trust}

Global organizations can benefit greatly from high quality IT communications systems and effective virtual teams. Many global organizations have access to advanced technology that allow virtual teams to share information quickly and efficiently. However, many organizations are now finding that technology is not enough. For virtual teams to be truly effective, members must be able to work well together. Behavioral studies are now beginning to determine that trust plays a critical role in the quality of collaboration between team members within a virtual team. Benetyte and Jatuliavičienè (2013) define trust as: "a voluntary exposure to the ill will of another, with a faith that no such ill will exists." They point out that by default, remotely distributed teams suffer from low levels of trust.

Differing cultures and experiences, as well as increased isolation of individual members, leads the team to have little faith that each member has no ill will. Trust cannot be improved with technology, but instead must be built by experience and time. Each member must be allowed to experience interactions with other members in order to formulate a basis of expectations for team mates' reactions. Newly created virtual teams often suffer from low trust because "the lack of past and future association decreases the potential existence of trust." For virtual teams, future associations are difficult to establish because humans typically require face to face interactions in order to establish solid relationships.

Unfortunately, the cost and time to meet frequently face to face meetings for virtual teams can often be prohibitive for many organizations. Therefore, organizations strive to improve trust via other means. One effective method of increasing trust is by identifying where the team has its greatest trust weaknesses and focusing on improvements. Increasing the quantity of communication between team members remotely and ensuring regular and frequent discussions can help build trust between team members. While this method may not prove to be as effective in promoting trust as face to face meetings, Benetyte \& Jatuliavičiene (2013) found that it is nonetheless effective and practical. With some effort, a virtual team may reach a level of effectiveness that allows the team to realize significant benefit for the organization.

Although team members within a virtual team may not reach the same level of trust as a traditional team, the blend of knowledge, experience, and culture of a virtual team can provide an organization productivity that could not be found with traditional teams. Furthermore, many global organizations need teams that can operate around the clock. By distributing virtual team members across multiple time zones, an organization can have access to a team that is always active.

NASA in 2003, in conjunction with MDA Robotics, in which virtual teams were used in a project to improve safety for space shuttle re-entry by enabling inspection of heat shielding while in orbit. NASA is a government-funded American organization, while MDA Robotics is a private firm based in Canada - the two organizations had dramatically different cultures. Due to the MDA Robotics members having cultural and organizational differences from their colleagues at NASA, the project nearly failed because the MDA Robotics members did not notify the NASA members when problems occurred: "a shortfall that manifested itself when the Canadian firm fell behind schedule" (Baker, 2007). 
In this case, members within the MDA team did not have a great deal of trust in their counterparts at NASA, and although both NASA and MDA Robotics certainly had access to technology that enabled quality communication and a high degree of interaction, the project nearly failed because of dissonance within the team. Again, although communications technology may be sufficient, virtual team members that do not actively participate and interact with each other will fall short time and time again.

\subsection{Organization of the Virtual Team}

The most likely cause for a failing virtual team is usually the team itself. As we have seen, trust is a vital factor for success or failure within a team. But there are other factors as well. Team organization also plays a key role in the quality and effectiveness of a virtual team. In his article, Lepsinger (2011) attempts to summarize the organizational problems that negatively affect a virtual team.

Leadership is the factor most important to the success of virtual teams (Lepsinger, 2011). This determination makes sense since quality leadership is necessary in order for virtual teams to develop trust and maintain open and frequent communication. A good leader can help provide common ground between members who have a high degree of cultural differences. Leaders can also help push the virtual team to continuously communicate and can step in when communication lags.

Leaders needs to establish clear goals and direct individual team members when confusion arises. If virtual teams don't have project goals and priorities in front of them, they can lose focus on these goals, causing problems down the road. Leaders needs to enforce and clarify roles and responsibilities among members within a virtual team. When virtual team members have a clear understanding of what direction and actions they need to take, it becomes easier for each member to trust their counterparts. Clear goals enable a higher degree of trust because it becomes clear that each member has a specific and unique duty, and conflicts are reduced.

There needs to be active cooperation and engagement between the virtual team members. Virtual teams that communicate frequently are more effective because they have higher degrees of trust. In the virtual team, it is important to foster a high degree of cooperation because "the lack of face-to-face contact can make the process of establishing trust and relationships even more arduous" (Lepsinger, 2011). Engagement is also important because isolated team members likely have poor visibility into the workings of their peers. This can cause many members to become unfocused and ineffective.

\subsection{Technology}

Almost everyone has had a problem with meeting software or a network connection during a critical virtual meeting. Such problems introduce extra "noise" that can inhibit communication. When it comes to working in virtual teams, technology can be both a saving grace and a hindrance. Armed with all kinds of tech solutions, teams remain challenged by complex workflows, tight deadlines, and geographical boundaries (Morio, 2015).

Several commercial companies have spurred as platforms for global corporations to organize, schedule and conduct online, web, video, and telephone conferences and meetings for a reasonable cost across national boundaries. To mention a few, amongst the commonly known in the United States of America, are WebEx.com, zoom. us, gotomeetings.com, logmein.com, GSuite.google.com, Vidyo.com, and slack.com (see Table 1).

\begin{tabular}{|l|l|}
\hline \multicolumn{2}{|c|}{ Table 1: Web Based Collaboration Platforms } \\
\hline Company & Description \\
\hline WebEx.com & $\begin{array}{l}26.5 \text { million meetings per month. 93\% of Fortune 100 company clients. 78\% of Fortune 500 company } \\
\text { clients. Specialized products to offer meetings, video conferences, events, webinars, or training. }\end{array}$ \\
\hline Zoom.us & $\begin{array}{l}750,000 \text { corporate clients. Up to 500video participants and 10,000 viewers at a time. Enterprise video } \\
\text { communications, with a secure, easy platform for video and audio conferencing, messaging, and webinars } \\
\text { across mobile, desktop, and room systems used around the world. }\end{array}$ \\
\hline Gotomeetings.com & $\begin{array}{l}16 \text { million users. 56 million online meetings. Meetings, video and web conferencing, chats, emails, and } \\
\text { desktop application and screen sharing using desktop and mobile devices. }\end{array}$ \\
\hline Logmein.com & $\begin{array}{l}\text { 200 million customer engagements. 2 million users per day. Offices located in USA, Australia, Hungary, } \\
\text { India, Ireland, and UK. Services include phone and video meetings, video conferencing, and collaboration } \\
\text { apps and software. }\end{array}$ \\
\hline GSuite.google.com & $\begin{array}{l}\text { Offers meetings, video conferences, training, storage, manages users, devices, and data, calendar, screen } \\
\text { share, real-time document edits, file sharing, and archives. }\end{array}$ \\
\hline Vidyo.com & $\begin{array}{l}\text { Mission is to deliver the world's highest quality, most innovative interactive video communication platform } \\
\text { and technologies at Web-Scale. Offices located in US, China, and France. }\end{array}$ \\
\hline Slack.com & $\begin{array}{l}8 \text { million users per week. 29 client companies on Fortune 100. 100 companies from 100 countries. Offices } \\
\text { located in US, UK, Canada, Australia, Japan, and Ireland. A platform that connects teams with the apps, } \\
\text { services, and resources around the world. }\end{array}$ \\
\hline Source: Compiled by Mehta and Shah from various sources of information, 09/01/2017. \\
\hline
\end{tabular}


Furthermore, apps and software tools for virtual collaborations are on the rise. To mention a few, amongst commonly known in the United States of America are Basecamp, Google Drive, Cloud, Dropbox, Skype, iDoneThis, Skitch, and others (see Table 2). Ryan Westwood (2015) emphasizes the importance of Cloud as a virtual collaboration tool. These digital tools support virtual collaboration through data storage, file sharing, real-time editing documents, pictorial annotations, chats, calendars, discussion webpage, progress tracking, to-do-lists, and other services (worksnug.com).

\begin{tabular}{|c|c|}
\hline Platform Name & Description \\
\hline Cloud & $\begin{array}{l}\text { A platform for data storage, management, analytics, security, and backup, } \\
\text { virtual collaborations, manage infrastructure, tools to work anywhere, and } \\
\text { protect users, devices, apps and data. }\end{array}$ \\
\hline Skype & $\begin{array}{l}\text { An app for day-to-day communications. Phone and video call, instant message, } \\
\text { and swap files. }\end{array}$ \\
\hline Basecamp & $\begin{array}{l}\text { A project management app. Hosts focused discussions on a dedicated project } \\
\text { webpage, tracks team's progress towards a goal, and manages to-do lists. Also } \\
\text { share calendars, files and collaborate on text documents. }\end{array}$ \\
\hline Google Drive & $\begin{array}{l}\text { Is the new home of Google Docs, which is Google's answer to Microsoft Office. } \\
\text { Collaborate on documents in real time, leave comments on team's work, or chat } \\
\text { while you work together. }\end{array}$ \\
\hline Dropbox & $\begin{array}{l}\text { With this software files are automatically updated, backed up, and can be shared } \\
\text { with secured pass code. }\end{array}$ \\
\hline iDoneThis & $\begin{array}{l}\text { A simple web app that's more about celebrating your team's achievements than } \\
\text { it is about spying on what's been done. It sends an evening email reminder that } \\
\text { everyone on your team writes a quick reply to saying what they did that day - } \\
\text { just one line per task. The next day, everyone gets a digest with what everyone } \\
\text { else has been working on. }\end{array}$ \\
\hline Skitch & $\begin{array}{l}\text { A too used to show rather than tell. Take a screen grab of what you can see on } \\
\text { your desktop or in your web browser and annotate it with shapes, arrows, quick } \\
\text { sketches and text. }\end{array}$ \\
\hline Join.me & $\begin{array}{l}\text { An app for show-don't-tell scenarios. Share your screen with up to } 10 \text { other } \\
\text { users, let them control your computer, chat and swap files. Good for showing } \\
\text { work in progress or for helping out team members with technical difficulties that } \\
\text { are hard to explain over the phone or over e-mail. }\end{array}$ \\
\hline \multicolumn{2}{|c|}{$\begin{array}{l}\text { Source: Information compiled by Mehta and Shah from various sources including worksnug.com, } \\
09 / 01 / 17 \text {. }\end{array}$} \\
\hline
\end{tabular}

Technology can help with communication. Team members can talk to one another with virtual messaging services, as well as being able to organize their work in a more central way. Having a central hub for messages and notes means that everyone can keep track of what is happening within the company. The most important thing to focus on with a virtual team is that everyone still works to the most efficient level that they can, so productivity must be kept as high as possible. It can be done by using technological enhancements. Having a central Customer Relationship Management tools to create tasks is a very good way of doing this so that everyone can see what they need to do next. With a project management tool, it can be ensured that the whole project is moving forward as planned. Marketing automation can also be used to ensure that the work flows steadily, and no one is stuck on a particular task (Ceresa, 2015).

However, technology cannot truly replace face to face human interaction. Even with advanced technology, organizations can benefit by investing in travel and face to face meetings when the expense can be met. Even infrequent yearly face to face meetings can do a great deal to solidify trust within a virtual team.

\section{Rethinking Management}

The role of management is to produce results for customers, shareholders, and employees -- it can be service to customers or value to shareholders or working conditions for employees. If management fails to deliver expectations to these widely diverse groups, the organization will fail. There is no difference between the management of organization with or without virtual teams. Having virtual teams put extra burden on management regarding managing virtual teams when they are located all over. Virtual team that must deliver the project, and what they "don't get" is what is expected to be delivered, or when it was due, or the costs. The sense of urgency is always missing (Dargin, n.a.).In her post 
(Dargin, n.a.) the author suggests six best practices for managing virtual teams: (1) communication management plan, (2) understand all the environments and cultures, (3) select appropriate technologies for interactions, (4) create a virtual personality and presence, (5) create places for unplanned interactions, and (6) effective virtual team meetings.

Management must think of culture for virtual teams and company. Company culture plays an important role in the success of virtual teams. By building and maintaining a strong and flexible company culture, a firm could overcome the challenges associated with virtual teams and virtual company (Kraus, 2016). The corporate culture of companies is increasingly influenced by the virtual modality of operations. Employees of a virtual company or working in a virtual workplace often find it difficult to identify the company culture (Van de Bunt-Kokhuis, n.a.). The virtual workplace will change the communication styles, interactions, and behavior of the employee and the corporate norms and productivity of an organization in the future.

As we have moved from manufacturing and agricultural economy to the digital economy, many U.S. companies have come to embrace a flat corporate structure, one that does away with middle management — or, sometimes, management altogether (Gotkin, 2012). Especially in start-ups and smaller companies in technology companies it seems that the most successful ones have no middle-management and a lack of formal coordinating mechanisms. It is recognized that this structure seems to be way better than the traditional top down structure for organizations with highly educated and autonomous professionals (Slob, n.a.). However, how do you manage virtual teams when there are no coordinating mechanisms? In the virtual corporation, where almost every employee is to one degree or another is leader. Managing virtual teams is challenging because one needs to create a corporate culture remotely (Baldassarre, 2015).

In virtual team, different people have different ways of going about tasks. We need more self- awareness management by virtual workers, more focused on making process work rather than getting credit for work done, establishing a vision for the organization rather than focusing on getting work done. The virtual team has to be built on levels of trust. Keeping up with group's needs, expectations and interest in challenging. The biggest failure in not receiving the benefits of virtual teams is that management has not changed. Management structure has to change from hierarchical to vertical.

\section{The New Kind of Worker}

In virtual organizations, many are non-traditional workers particularly individuals work from all over the world. Many of them neither have a job security or company's benefit package. They do not have any loyalty to the organizations they are working for and same way organizations does not have any loyalty to them since they are not a regular employee.

Employees working in virtual teams are diverse geographically, they are isolated from their colleagues. Although they may have contact with other team members, they hardly know them. In this situation, the virtual worker loses opportunities to learn from his or her closest colleagues (Snyder, 2003).

The virtual organization is a learning organization. For an organization to survive in the new business environment, everyone has to learn together and share the skills and knowledge. Some virtual team members will spend more time or interact with customers in other part of the word than its colleagues. Some of them will have new team leaders frequently due to the nature of the business and changing economy. How does one working from home or café will feel part of an organization or belonging? Specifically, when flux and flexibility is the norm in the virtual organization, how does worker will react to the constant change or not feeling part of the organization?

This new type of worker as well as the organization they work for have to be flexible.

\subsection{Virtual Global Collaboration Advantages}

The primary advantage of virtual collaborations are lower overhead cost, high employee satisfaction, higher scalability, and increase in efficiency. By running the business virtually, it is not necessary to worry about leasing office space, buying furniture, costs of utilities, heating and air conditioning for employees, and other related expenses. Because of a need or desire for flexible hours, more talented employees than ever are looking for jobs where they can work from home. This gives companies increased opportunities to hire talented team members from around the world who might not otherwise be able or willing to work for the company. Through the virtual workplaces, companies do not require office space or do not need to worry about moving to larger office building with the growth of the company and the number of employees. As long as employees work in an environment that they comfortable with, for example, from home or neighborhood café, they will be more productive. The virtual workplace also allows the working mothers with family/kids at home to be a productive member of the labor force while being a productive member of the family. 
The virtual collaborations allow the formation of multicultural teams based on the pool of talents from around the world. The advantages of multicultural teams to global firms include deep knowledge of different product markets, culturally sensitive customer service, and 24-hour work rotations (Brett, Behfar, \& Kern, 2016).

\subsection{Virtual Global Collaboration Disadvantages}

The primary disadvantages of virtual global collaborations are lack of cohesiveness, lack of camaraderie, risk to reputation, and security and compliance issues. Often the virtual teams choose their own work hours, which might fragment the organization. For example, if there's an emergency, such as a major equipment failure or a serious IT issue, calling a meeting of the entire organization to deal with such crises and finding solutions would be very difficult. Social interaction does help encourage more effective teamwork. In a virtual environment, however, there aren't enough opportunities for employees to gather for impromptu conversations that can often enhance collaboration. If potential customers find out that you run a virtual office with remote employees, they may not think of your firm as a "real" company or may not take company's business serious. In some industries, it is extremely risky to have confidential information stored remotely. For example, the accidental loss or release of data in specific industries, such as financial services and healthcare, can carry serious repercussions.

\section{Building the Virtual Team}

How does a manager go about building an effective virtual team? As we have seen, it is important to deliver tools that enable the team to communicate efficiently and frequently. Video communications, whiteboard applications, and collaboration tools are all important components to a quality IT system that allows a virtual team to work well together. But what factors should an organization look for when choosing members for a virtual team? According to Barnwell, et.al, (2014) in "Leadership of International and Virtual Project Teams," there are a number of important factors that should go into choosing candidates for a newly created virtual team.

A manager should not only consider traits that would make a candidate effective in a traditional team, but also should take into account other aptitudes, such as cultural sensitivity, problem and goal orientation, and self-esteem. These aptitudes are particularly important for project managers, who will routinely be working with all the members of the virtual team. The project manager is a critical component of a virtual team and must be carefully chosen. "As the leader of the team, the project manager's role is to establish a team culture that takes into account the dynamic environment of global projects." (Barnwell, Nedrick, Rudolph, Sesay, \&Wellen, 2014)

It is important for a manager to embrace the cultural differences within a virtual team, as they enhance the team, and allow the team to more easily adjust to any global demands the organization might face. As Barnwell, et.al, (2014) discuss, cultural differences between countries can vary substantially. In the interview with the Global Quality Manager for Schlumberger, they reveal some excellent examples of cultural diversity in business, and how those differences can impact an organization. This interview identified differences in how business is conducted in Central, North and South America, Asia, and the Middle East. With a deep understanding of these cultural differences, an organization can position itself competitively.

\section{Conclusions}

Currently, industries are seeing a significant increase in the trend of globalization. More and more Internet based organizations are now depending on $24 / 7$ performance. Furthermore, emerging markets are popping up around the world. Many organizations are relying upon distributed virtual teams in order to effectively manage these new trends. Distributed teams can more easily deal with $24 / 7$ availability. Such teams also are seen as a favorable response to globalization because of the increased variability of culture within them. Teams with blended cultures are better equipped to deal with cultural barriers in emerging markets, just as they are more apt to handle managing global requirements.Virtual collaborations have changed the landscape of the global meeting space. On one hand, a new type of worker, included is a millennial, has to be malleable. On the other hand, the global organizations whom they work for has tobe flexible and accommodate the lifestyle and mind-set of a new type of worker.

The true challenge for organizations is to implement virtual teams in a manner that is effective. Both technology and trust are critical to forming effective virtual teams. Technology enables virtual teams to communicate frequently, with high bandwidth, and allows members to not only share their voice, but more detailed information such as designs, concepts, videos, models, and real time interactions. Virtual teams have the potential to be very effective and successful. It is imperative that the companies who choose to utilize such teams understand that they must implement steps that help foster strong communication, build trust and respect among team members, and understand that there are cultural and language differences. If these obstacles can be overcome, virtual teams will have the ability to change how day to day operations are done, thus increasing the profitability of the company. 
With the changing times and advances in digital technologies, the importance of one's physical location on earth is diminishing and the existence in the cyber world is increasing. The new kind of worker is more interested in interactions via social media tools, managing project, and results rather than physical presence, social interactions in person, and managing time and activities.

The future belongs to Dispersed (virtual) teams; collected teams (physical) will be thing of the past. With the right tools, strategies, and attitudes, success of the virtual workplaces and collaborations will continue to grow resulting in to increased number of virtual companies in the future.

\section{Information about the Authors:}

Dr. Kamlesh Mehta is an internationally known professor, research scholar, administrator, consultant, and business owner. Currently, Dr. Mehta is the Chair of the Department of Management and Marketing and a Professor of International Business and Marketing at National University in California. He is a frequent visiting professor at Indian Institute of Management (IIM). As a research scholar, the Harvard Business School Publisher has recognized Dr. Kamlesh Mehta in The International Directory of Business and Management Scholars and Research in the United States. In his decades of academia and global business experiences, Dr. Mehta has published over 50 scholarly research papers in Journals and proceedings, ten of which have earned him outstanding research awards. Dr. Mehta's educational background includes Doctor of International Business and Master of Business Administration from United States of America. Recently, he completed "The Art and Craft of Discussion Leadership", a certificate program from Harvard Business School, USA.

Dr. Vivek Shah is professor in the Dept. of CIS \& QMST at Texas State University. He holds a Ph. D. from University of North Texas. His research interests include use of information technology in communication, embedding of information systems issues in global environment and non-linear regression. He is the author or co-author of more than 25 referred articles. He has published articles in The Journal of Computer Information Systems, Kybernetes: The International Journal of Systems \& Cybernetics, Journal of Education for Business, IEEE transactions and other journals.

\section{Global Business: Virtual Workplaces and Collaborations}

\section{Note: The following abstract of the full paper was published as follows:}

Mehta K.T., \& Shah, V. (2017) "Virtual Global Workplaces and Collaborations: A Future Trend". A presentation and an abstract publication in the proceedings of the 11th Decision Sciences Institute-Indian Subcontinent Chapter conference, December 27-31, 2017, at Indian Institute of Management in Tiruchirappalli, India, pg. 44.

\section{References}

Baker, E.(2007).When Teams Fail: The Virtual Distance Challenge.Strategy+Business,[Online] Available: https://www.strategy-business.com/article/li00026?gko=68945, May 17.

Baldassarre, Rocco. (2015). 10 Ways to Successfully Manage Virtual Teams. [Online] Available: https://www.entrepreneur.com/article/244197\#, March 24.

Barnwell, Dwayne., Nedrick Shea., Rudolph, Elizabeth., Sesay, Mohamed., \&Wellen, William. (2014). Leadership of International and Virtual Project Teams.International Journal of Global Business, 7:2, pp. 1-8.

Benetytė, D., and Jatuliavičienėm, G. (2013). Building and Sustaining Teams within Organizational Context.Regional Formation \& Development Studies, 2, 10, pp. 18-30.

Brett, Jeanne., Behfar, Kristin., \& Kern, Mary. (2006). Managing Multicultural Teams. Harvard Business Review,November, 84:11, pp. 84-91. Available: https://hbr.org/2006/11/managing-multicultural-teams

Ceresa, Alessandra. (2015). The Importance of Technology in Virtual Teams.Business 2 Community, December 14. [Online] Available:http://www.business2community.com/human-resources/importance-technology-virtualteams-01396719\#J4HsivWM7L4GHOEy.97

Dargin, Star. (n.a.). Top 6 Practices for Managing Virtual Teams.Corporate Education Group.[Online] Available: http://www.corpedgroup.com/resources/pm/6BestPracticesMVT.asp

Ferrazzi, K. (2014). Getting Virtual Teams Right. Harvard Business Review,HBRBlog,December. [Online] Available: https://hbr.org/2014/12/getting-virtual-teams-right

Ferrazzi, K. (2012).How Successful Virtual Teams Collaborate,Harvard Business Review, HBR Blog, October 24. [Online] Available: https://hbr.org/2012/10/how-to-collaborate-in-a-virtual

Gotkin, Zev. (2012). America's Innovative Companies Are Going Flat. Huffpost, December 17. [Online] Available:http://www.huffingtonpost.com/zev-gotkin/corporate-hierarchy-work_b_1962345.html 
Kraus, Josh. (2016). How To Create a Strong Company Culture in a Virtual Workplace, January6. [Online] Available:http://www.skilledup.com/insights/create-strong-company-culture-virtual-workplace.

Lepsinger, R. (2011). Virtual Team Failure: 6 Common Missteps That Threaten Your Team's Success. Communications Briefings, February, pp. 6.

May, A., and Carter, C. (2001)A Case Study of Virtual Team Working in the European Automotive Industry. International journal of Industrial Ergonomics, 27 (3), pp.171-186.

Morio, Jason. (2015). Fulfilling the Technology Needs of Virtual Teams.Real Time Communications, September 14. [Online]

Available:

http://www.realtimecommunicationsworld.com/topics/realtimecommunicationsworld/articles/409843fulfilling-technology-needs-virtual-teams.htm

Rahayu. (2019). The Impact of Working Environment, Work Stress, and Competency toward Employee Performance. Journal of International Business and Economics, June, Vol. 7, No. 1, pp. 26-33 ISSN: 2374-2208(Print), 2374-2194(Online), Available:http://jibe-net.com/journals/jibe/Vol_7_No_1_June_2019/4.pdf

Slob, Angelique. (n.a.). Why the Flat Organisation Is The Best Structure for Tech. [Online] Available: https://pinqconsult.com/why-the-flat-organisation-is-the-best-structure-for-tech/

Snyder, Bill. (2003). Research: Why Some Workers Fear for Virtual Teams. Insights By Stanford Business, October 1. [Online] Available: https://www.gsb.stanford.edu/insights/research-why-some-workers-fear-virtual-teams

Van de Bunt-Kokhuis, Sylvia. (n.a.). The virtual workplace and the company culture - Employee oriented tools to build a corporate web culture. [Online] Available:http://www.managementsite.com/261/The-virtualworkplace-and-the-company-culture.aspx

Westwood, Ryan. (2015). 4 Reasons To Get Excited About Cloud Technology In The Workplace. Forbes, Mar 13. [Online] Available: http://www.forbes.com/sites/ryanwestwood/2015/03/13/4-reasons-to-get-excited-aboutcloud-technology-in-the-workplace/\#656a60ad7943.

Worksnug.com. (n.a.). 7 Best Collaboration Tools for Virtual Teams. [Online] Available:http://worksnug.com/blog/7best-collaboration-tools-for-virtual-teams. 